\title{
Is It Safe (and When) to Stop Oral Anticoagulation After Ablation for Atrial fibrillation? (Do We Have Enough Evidence to Solve the Dilemma?)
}

\author{
José Luis Merino ${ }^{1}$ · Juan Tamargo²
}

Accepted: 21 August 2021 / Published online: 7 September 2021

(c) Springer Science+Business Media, LLC, part of Springer Nature 2021

Atrial fibrillation (AF), the most common sustained cardiac arrhythmia, is associated with significant impairment in functional capacity and quality of life and increased morbidity and mortality [1-3]. Indeed, AF is independently associated with an overall 3.5-fold risk increase of mortality, which is predominantly due to increased risk of stroke and systemic embolic events (S/SE) and ventricular dysfunction [4]. Non-anticoagulated patients with AF have a 3- to 5 fold increased risk of ischemic strokes, and it is estimated that up to $30 \%$ of all ischemic strokes and $10 \%$ of cryptogenic strokes are related to this arrhythmia [1-3]. Furthermore, ischemic strokes associated with $\mathrm{AF}$ are nearly twice as likely to be fatal and generally more severe and more recurrent than strokes unrelated to $\mathrm{AF}[5,6]$.

Catheter ablation of AF (CAAF) is an effective therapeutic strategy recommended in clinical practice guidelines (CPGs) as a first-line rhythm control therapy in selected patients with symptomatic paroxysmal and persistent AF with and without risk factors for AF recurrence or as a second-line rhythm control therapy, being an alternative to class I or III antiarrhythmic drugs when these drugs failed or are contraindicated $[1-3,7]$.

When performed by well-trained operators, CAAF is a safe and superior alternative to antiarrhythmic drug therapy for reducing arrhythmia burden and improving quality of life in patients with symptomatic AF [7-9]. However, randomized clinical trials (RCTs) have not clearly demonstrated a significant reduction in all-cause mortality, stroke, or major

Juan Tamargo

jtamargo@med.ucm.es

1 Arrhythmia \& Robotic EP Unit, Hospital Universitario La Paz-IdiPaz, Madrid, Spain

2 Department of Pharmacology and Toxicology, School of Medicine, Universidad Complutense, Instituto de Investigación Sanitaria Gregorio Marañón, CIBERCV, 28040 Madrid, Spain bleeding event (MBEs) following CAAF, and, therefore, the indications for this procedure have not been broadened beyond symptom relief, except to reverse left ventricular dysfunction when tachycardiomyopathy is highly probably [7-11]. Nevertheless, the CASTLE-AF trial found that CAAF reduced the risk of death and heart failure hospitalization compared with medical therapy in selected patients with heart failure with reduced ejection fraction (HFrEF) [12], a result confirmed in other studies [13, 14]. Restoration of sinus rhythm also improved left ventricular ejection fraction, functional capacity, and ventricular remodeling [15]. However, the benefit associated with CAAF appeared to be more modest in routine practice than that reported in the CASTLE-AF trial [16], and, in addition, some authors have raised criticism about the selected population enrolled in the trial. Two recent systematic reviews and meta-analysis found that CAAF was associated with a mortality benefit as compared with medical treatment, and this benefit was restricted to patients with $\mathrm{AF}$ and $\mathrm{HFrEF}[17,18]$.

Although CAAF is considered a relatively safe invasive procedure, it can be occasionally complicated by periprocedural thromboembolic ( $\mathrm{S} / \mathrm{SE}$, transient ischemic attacks-TIA) and bleeding events [1-3], even when some complications can also occur weeks or months following ablation. CAAF is a complex interventional procedure that involves catheter manipulation and ablation in the delicate thin-walled atria, trans-septal punctures, left atrial (LA) endothelial damage, char formation on ablation catheters, air bubble ingress, a prothrombotic state associated with the arrhythmia, activation of the clotting cascade, and blood flow alteration after sinus rhythm is established [19]. These changes increase the risk of S/SE during and for several weeks after ablation even in patients considered to have a low-risk of stroke according to the tools for risk assessment ( $\mathrm{CHADS}_{2}, \mathrm{CHA}_{2} \mathrm{DS}_{2}-\mathrm{VASc}$, and ABC scores) [7-9, 20].

Prospective, registry-based data show that up to $14 \%$ of patients undergoing CAAF experience complications, 2-3\% 
of which are potentially life-threatening [7, 11, 21, 22]. Several surveys enrolling mainly paroxysmal AF patients undergoing CAAF showed an incidence of thromboembolic events $<1.0 \%$, but asymptomatic cerebral embolism can appear in $5-15 \%$ and bleeding complications in $1-4 \%$ of patients $[7,11,20]$. Thus, adequate oral anticoagulation therapy (OAT) is recommended before (for at least 3 weeks in case of stroke risk factors), during, and for at least 2 months post-CAAF to prevent these thromboembolic complications even at the risk of increasing bleeding events [1-3].

\section{Oral Anticoagulant Therapy}

To date, OAT is the only therapeutic intervention that has shown to improve survival in patients with AF. For almost 50 years, adjusted doses of vitamin $\mathrm{K}$ antagonists (VKAs, mainly warfarin) were the mainstay OAT prescribed for the prevention of S/SE in AF patients. Today, VKAs are still used in many patients and are the only OAT recommended in those with moderate-to-severe mitral stenosis and/or prosthetic mechanical valves [1-3]. In a meta-analysis of 9 studies (27,402 patients), CAAF performed under therapeutic warfarin (international normalized ratio-INR 2.0-3.5) was associated with a striking decrease of S/SE (OR, 0.10; 95\% CI, 0.05-0.23; $P<0.001)$ and minor bleeding complications (OR, $0.38 ; 95 \% \mathrm{CI}, 0.21-0.71 ; P=0.002$ ) compared with warfarin discontinuation and did not increase the risk of MBEs, including cardiac tamponade [23]. In the COMPARE study, which recruited patients at high-risk of stroke (24\% had persistent AF and 51\% long-standing persistent $\mathrm{AF} ; \approx 70 \%$ with a $\mathrm{CHADS}_{2}$ score $\geq 2$ ), uninterrupted warfarin therapy reduced periprocedural stroke/TIA and minor bleeding complications, as long as the INR remained within the therapeutic range (TTR) $\geq 70 \%$ of the time, while warfarin temporary discontinuation with enoxaparine bridging emerged as a strong predictor of periprocedural S/SE [24]. However, the use of VKAs is limited by their multiple mechanisms of action, slow onset/offset of action, narrow therapeutic range, wide inter-individual variability in anticoagulant response, need for regular INR monitoring and dose adjustments to optimize the TTR, and multiple drug interactions [25].

New direct oral anticoagulants (DOACs: apixaban, dabigatran, edoxaban and rivaroxaban) present a more targeted mechanism of action, rapid onset-offset of action, predictable anticoagulation effects so that they can be used at fixed doses without regular monitoring and fewer drug interactions. Thus, in patients on VKAs with a low TTR $(<70 \%)$ at follow-up, switching to a DOAC is recommended [1-3]. In four pivotal phase 3 RCTs in patients with NVAF, compared with warfarin, DOACs significantly reduced S/SE (19\%) mainly driven by a reduction in hemorrhagic stroke
(51\%), intracranial hemorrhage (52\%), and all-cause mortality $(10 \%)$ but increased gastrointestinal bleedings $(25 \%)$ at long term follow-up [26]. Thus, DOACs are more convenient for both patients and physicians and are replacing VKAs in general practice, including patients undergoing CAAF. Several clinical trials [27-32] and meta-analysis (Table 1) [33-42] comparing the use of uninterrupted DOAC vs. warfarin therapy for CAAF reported no differences in the incidence of stroke/SE/TIA or minor bleeding events, but DOAC therapy was associated with reduced risk of MBEs, which translated into a significant net clinical benefit. Thus, unless they are contraindicated (i.e., patients with moderateto-severe mitral stenosis and/or mechanical heart valves), uninterrupted OAT with DOACs is preferred to VKAs for $\mathrm{S} / \mathrm{SE}$ prevention in patients undergoing CAAF [1-3]. However, and because of their short half-lives (10-14 h), it is critical to educate the patient about the importance of strict adherence to the prescribed regimen.

The selection of OAT before CAAF should be based on the risk of thromboembolic complications, irrespective of the pattern of AF (paroxysmal, persistent, permanent), and individualized after discussion of the efficacy and risks of thromboembolic and bleeding events as compared with antiarrhythmic drug therapy, taking into consideration the patient's values and preferences [1-3].

\section{Recommendations in Current Practical Clinical Guidelines}

CPGs recommended that AF patients with stroke risk factors should receive uninterrupted preprocedural OAT with VKAs (INR 2.0-3.0) or DOACs for at least 3 weeks before $\mathrm{CAAF}$ and to perform the procedure without OAT interruption [1-3]. However, some authors consider that it is reasonable to hold one to two doses of the DOACs prior to ablation with reinitiation of OAT postablation $[55,56,57]$. After CAAF, CPGs recommend continuing OAT for S/SE prevention for at least 2 months in all patients regardless of stroke risk factors [1-3]. Beyond this time, the decision to continue or stop OAT should not be based on the apparent success or failure of CAAF or pattern of AF, but on the stroke $\left(\mathrm{CHA}_{2} \mathrm{DS}_{2}\right.$-VASc score) and bleeding risks (HASBLED score) and comorbidities of the patient $[1,2,3,58]$. However, the estimated bleeding risk, in the absence of absolute contraindications to OAT, is not recommended to guide the decision to use OAT for stroke prevention (3).

The recommendation of long-term OAT therapy for S/ $S E$ prevention is maintained in patients at high risk of stroke (i.e., $\mathrm{CHA}_{2} \mathrm{DS}_{2}$-VASc score $\geq 2$ for men or $\geq 3$ for women, prior history of stroke), in whom the reduction in the risk of a disabling stroke may outweigh the risk of bleeding [1-3]. For patients with intermediate stroke risk $\left(\mathrm{CHA}_{2} \mathrm{DS}_{2}-\mathrm{VASc}\right.$ 


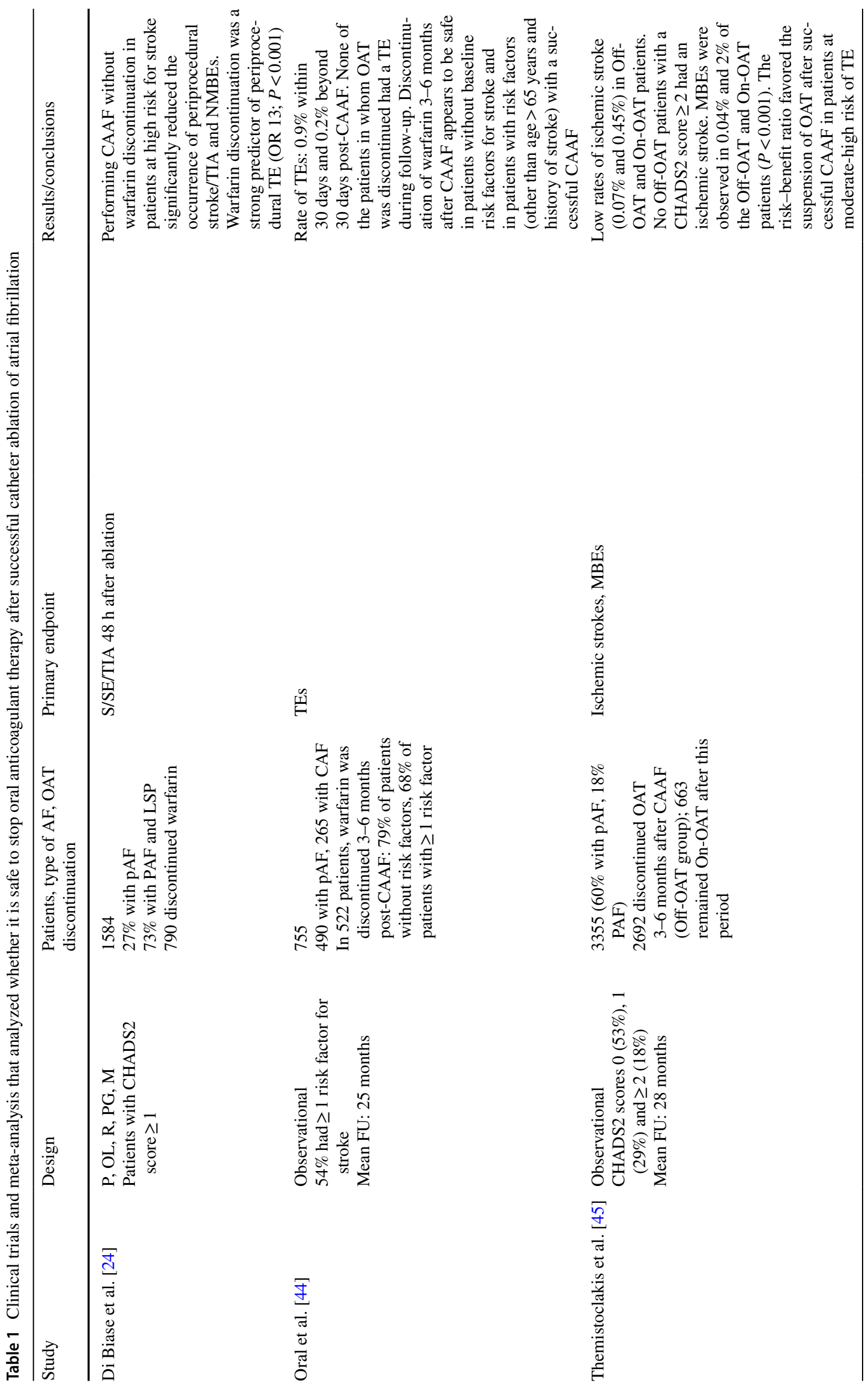




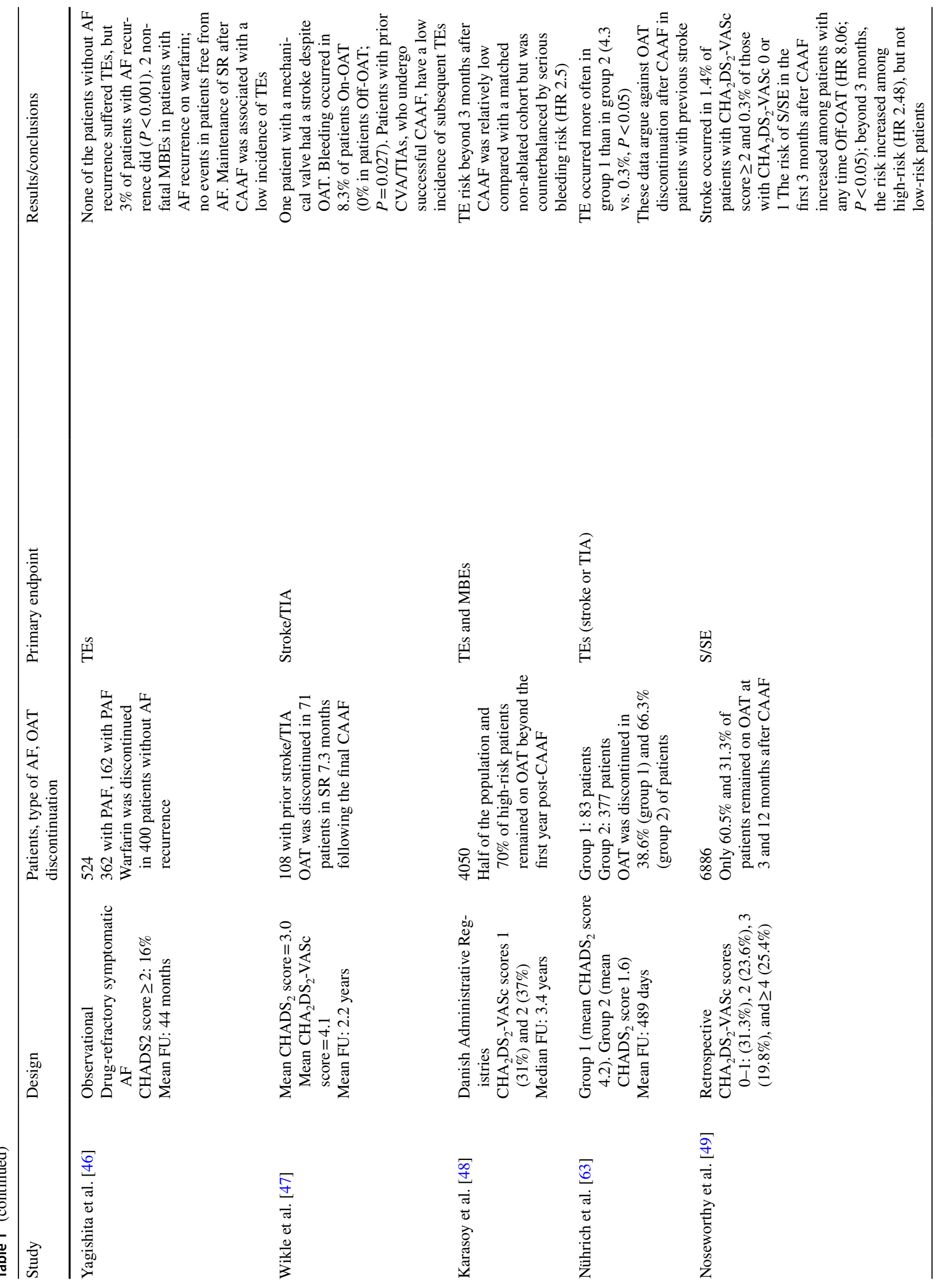




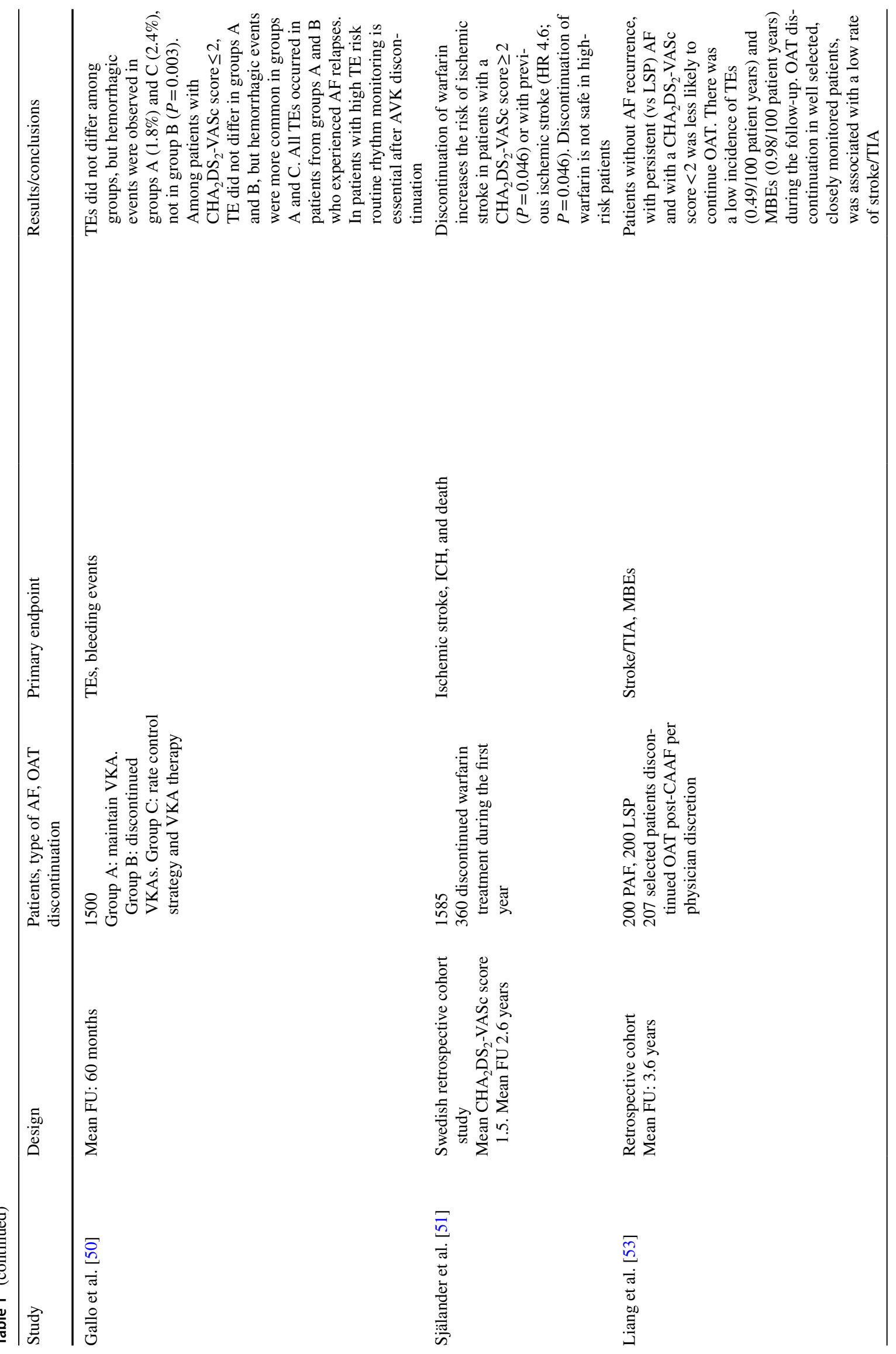




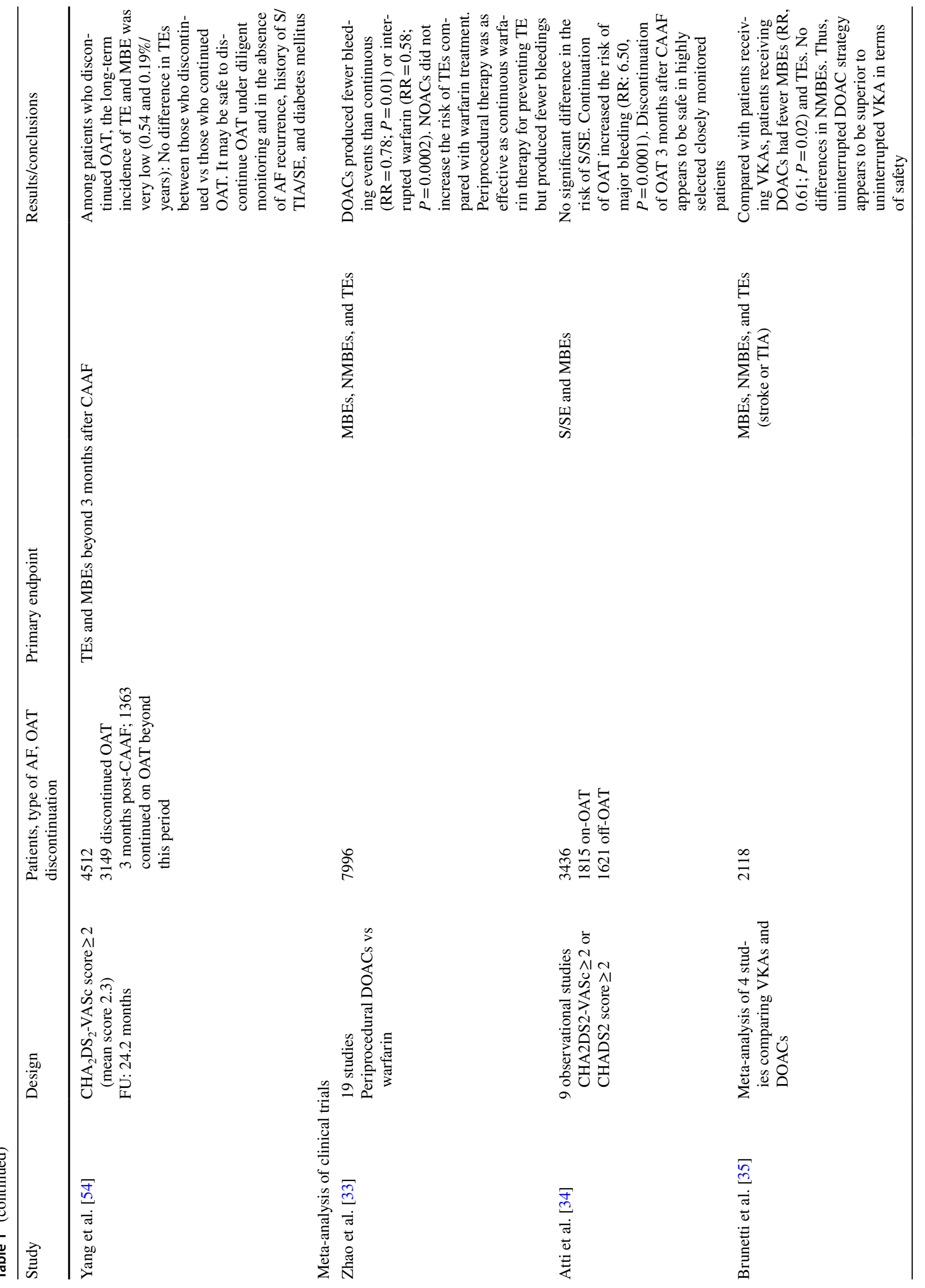




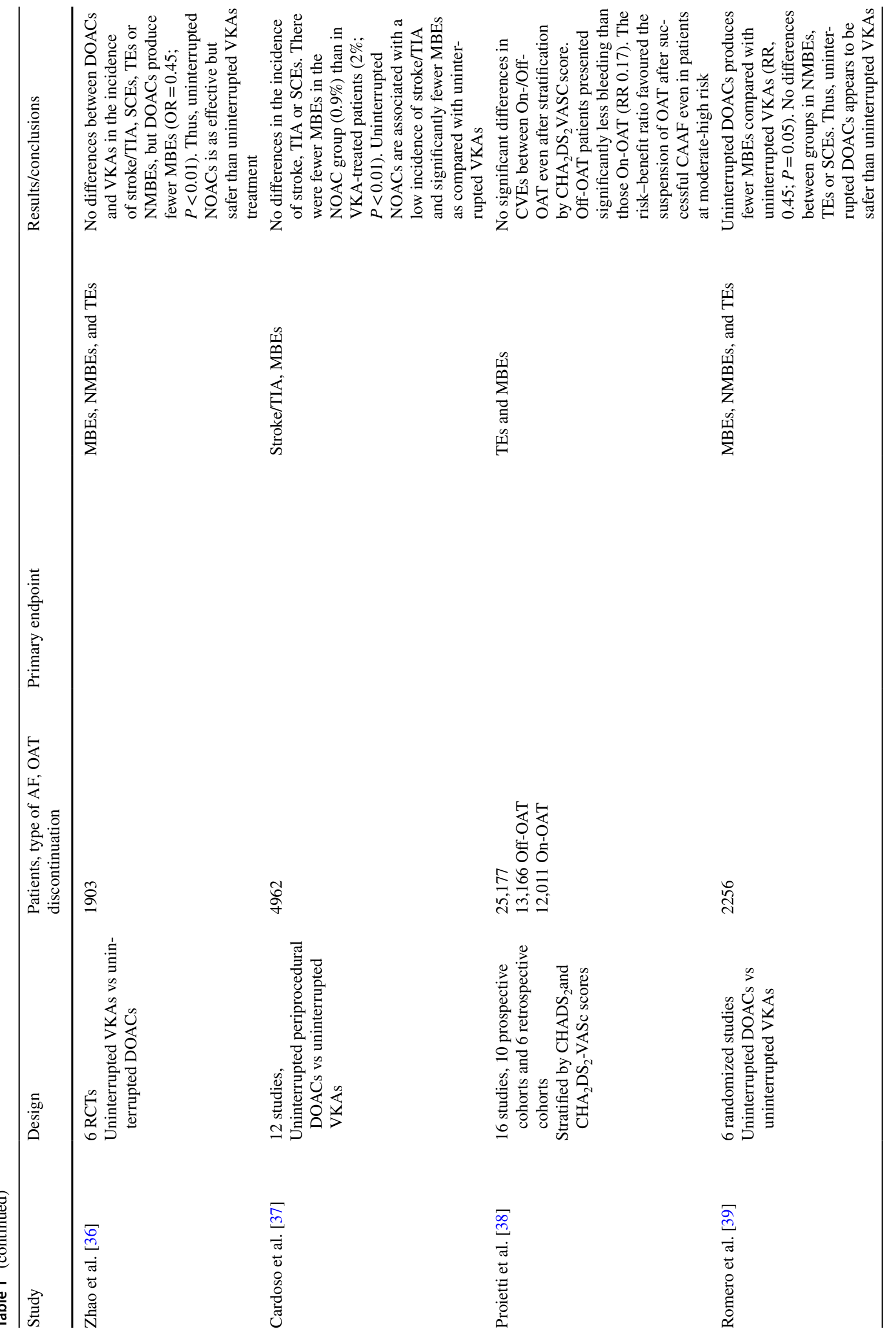




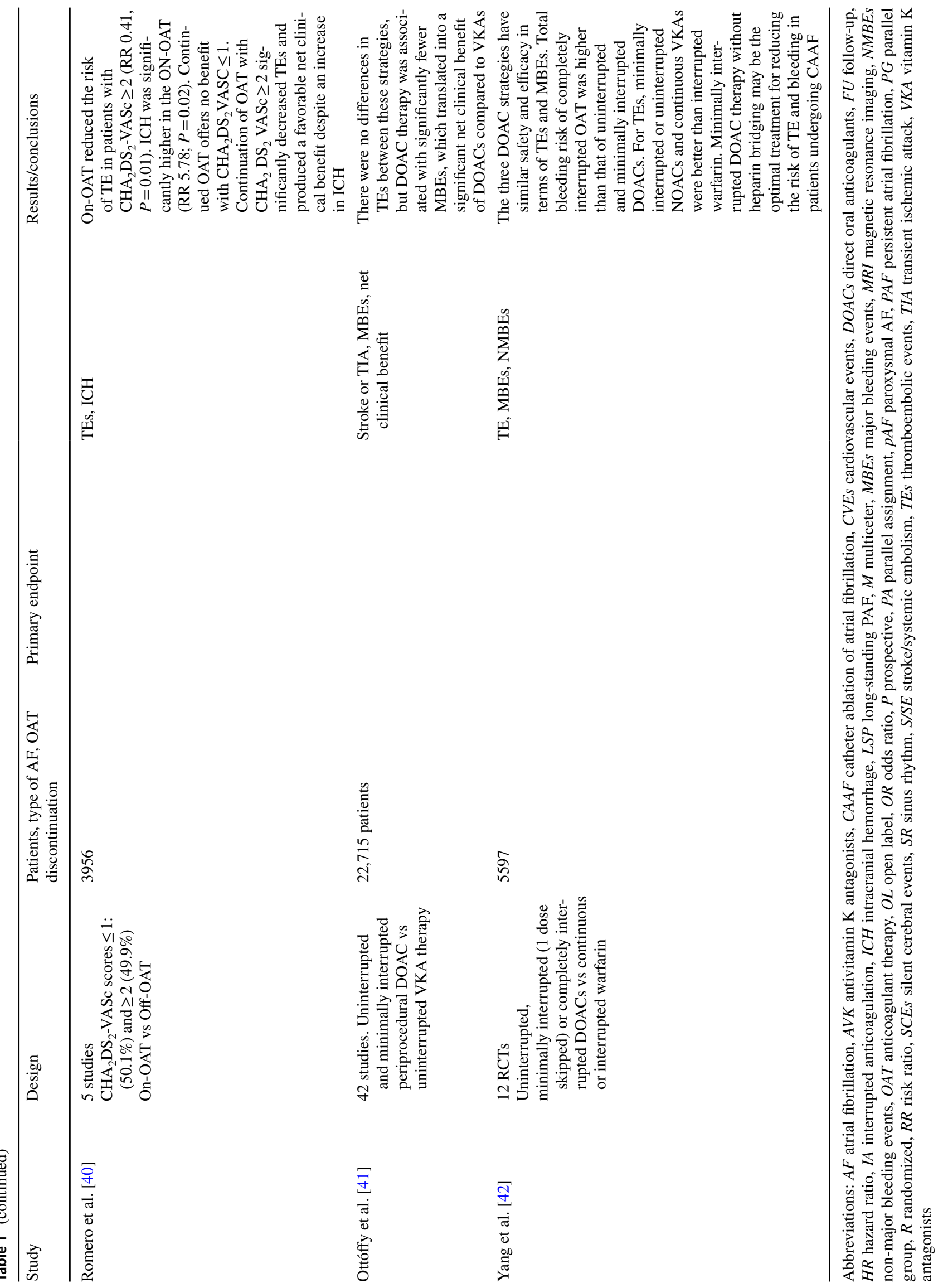


score 1 in men or 2 in women), long-term OAT therapy is also recommended. However, because of lack of RCTs to guide OAT therapy, some physicians consider that in selected patients without AF in whom a diligent follow-up of AF recurrences is performed, OAT therapy can be discontinued based on net clinical benefit (risk of S/SE weighed against the risk of bleeding) and taken into consideration patient's values and preferences [59,52]. Finally, in patients at low risk of stroke $\left[\mathrm{CHA}_{2} \mathrm{DS}_{2}\right.$-VASc score $=0$ (men), or 1 (women)], the risk of S/SE in observational studies is very low $(0-0.2 \%)$, and the risk of bleeding associated with longterm OAT outweighs the benefits of stroke prevention; thus, discontinuation of OAT should be considered 2 months postCAAF regardless of AF recurrence [40,60,61,62].

\section{Do We Follow the Clinical Guideline Recommendations?}

An important question to answer is whether the recommendations of the CPGs are regularly followed. Despite the recommendation for continued OAT in patients at moderatehigh risk of stroke, real-world patterns of OAT therapy in these patients are heterogeneous. In some studies, $\approx 1$ in 4 patients with a $\mathrm{CHA}_{2} \mathrm{DS}_{2}$-VASc score $\geq 2$ had their OAT discontinued sometime after ablation with no safety strategy in place [63,64]]. Thus, discontinuation of OAT after ablation is common and physicians (including some members of the writing committee of CPGs) are not following the recommendations on post-ablation OAT, and the clinical consequences of this conduct remain uncertain. This finding confirms that recommendations are commonly not being followed in clinical practice, reflecting the lack of randomized trial data to guide practice. Thus, there is a critical need to further evaluate the association between discontinuation of OAT post-CAAF and subsequent outcomes.

\section{Do We Have Enough Data to Recommend that It Is Safe to Discontinue OAT After Catheter Ablation of Atrial Fibrillation?}

To answer this question, a systematic review in PubMed, EMBASE, SCOPUS, and Google Scholar up to December 31,2020 , was performed to identify studies comparing continuation vs discontinuation of OAT after an apparent successful CAAF using the following heading terms and key words: atrial fibrillation, ablation, catheter ablation, warfarin, vitamin $\mathrm{K}$ antagonist, direct oral anticoagulants, apixaban, dabigatran, edoxaban, rivaroxaban, factor Xa inhibitors, direct thrombin inhibitors, stroke, thromboembolism, major and minor bleeding, and combinations of these keywords. Clinical outcomes included cerebrovascular events, systemic thromboembolism, major/minor bleeding, and net clinical benefit.

Several retrospective non-randomized studies [24, 43-53] and meta-analysis [33-42] examined whether it was safe to discontinue OAT after successful CAAF using the $\mathrm{CHA}_{2} \mathrm{DS}_{2}$-VASc score for risk stratification and S/SE as the primary outcomes (Table 1). Some studies reported a low risk of S/SE $(0.8-1.1 \%)$ and a lower risk of serious bleedings in patients who discontinue OAT several months after CAAF [43-47, 50, 52, 53]. Conversely, other studies confirmed that OAT discontinuation after CAAF is not safe in high-risk patients [23, 47-49, 51, 53]. However, these studies presented important limitations which are summarized in Table 2, and, therefore, their conclusions should be interpreted carefully and need to be confirmed in properly designed prospective RCTs that assess the efficacy and safety of discontinuing OAT after CAAF. Thus, at the present time, there is no information from prospective RCTs to recommend whether it is safe or not to discontinue OAT after CAAF in patients with intermediate-to-high stroke risk.

Proietti et al. permorfed systematic review of 10 prospective cohort and 6 retrospective cohort studies $(25,177$ patients) that reported cerebrovascular events (CVE) after CAAF and compared patients on- vs off-OAT [38]. No significant differences in the incidence of CVE emerged between on- and off-OAT patients after CAAF, and this result persisted after stratification by $\mathrm{CHADS}_{2}$ and $\mathrm{CHA}_{2} \mathrm{DS}_{2}$-VASc score. Off-OAT patients suffered significantly less bleeding than those on-OAT (RR, 0.17; CI, 0.09, 0.34), but they have lower $\mathrm{CHADS}_{2}$ scores than on-OAT, probably reflecting the reluctance of clinicians to discontinue OAT in high thromboembolic risk patients and the influence of current guidelines. However, it should be mentioned that there was a high degree of heterogeneity among the studies, all the studies but two used warfarin as OAT (so, it is uncertain whether these results can be extrapolated also to DOACs), and they did not provide sufficient data to predict the risk of bleeding (e.g., HAS-BLED scores) or assess the impact of AF recurrence on the incidence of CVE in the studied population.

\section{Is It Possible to Stop OAC Therapy Post-Successful Ablation?}

In this sea of doubts, it seems reasonable to recommend caution against discontinuation of OAT after an apparently successful CAAF in patients with a $\mathrm{CHA}_{2} \mathrm{DS}_{2}-\mathrm{VASc}$ score $\geq 2$ []. Of note, many recently diagnosed healthy AF patients develop cardiovascular diseases with a consequent change in thromboembolic risk profile within a short time frame. A close follow-up of these patients is needed to avoid over- and under-treatment with OAT. 
Table 2 Main limitations of present evidence

- Most clinical studies were retrospective and/or non-randomized, which can introduce potential performance bias

- In the absence of a randomized comparison of chronic OAT versus discontinuation of OAT after CAAF definite conclusions are not possible

- There are significant differences among trials design, stroke risk of participants, pattern (paroxysmal vs persistent) of AF, dosing regimens of DOACs, ablation techniques, and follow-up duration

- The time frame of discontinuation of OAT ranged from 3 to 8 months at the discretion of the physician

- Episodes of silent AF can be underestimated due to lack of continuous ECG monitoring during follow-up

- The definition of bleeding was not consistent throughout the studies

- No pre-ablation magnetic resonance imaging was performed to evaluate the presence of any pre-existing cerebral ischemic lesions

- Only a small subset of patients had a $\mathrm{CHA}_{2} \mathrm{DS}_{2}$-VASc score $\geq 2$, and a reduced number of patients were at extreme increased stroke risk due to a prior stroke or TIA

- The short overall follow-up duration does not allow to evaluate the effect of AF recurrences on thromboembolic events (S/SE) and bleeding complications

- Meta-analysis are biased and underpowered due to the relatively small sample sizes and the low event rates of the studies

- There are no head-to-head comparative studies among DOACs, even when they present important pharmacodynamic/pharmacokinetic differences

- DOACs were studied in a relatively young population of AF patients (mean age 62 years), but there is little information in older patients (>75 years) or in patients with chronic kidney disease, at higher risk of bleeding complications

- Relevant studies were conducted at high-volume centres with low adverse event rates, but procedural risks for both bleeding and stroke might be higher at low-volume centres with less procedural experience

- The temporal dissociation between AF episodes and stroke suggests that some strokes may not be caused by AF directly, but AF simply represents a marker for other other stroke risk factors and vascular mechanisms with which AF is frequently associated

Abbreviations: $A F$ atrial fibrillation, $C A A F$ catheter ablation of atrial fibrillation, DOACs direct oral anticoagulants, $O A T$ oral anticoagulant therapy, $S / S E$ stroke/systemic embolism, TIA transient ischemic attack

The question is how to determine the cut-off amount of AF to be considered an AF recurrence for which OAT should be continued or reinitiated. A recent retrospective study evaluated the rates of stroke/SE as a function of both $\mathrm{CHA}_{2} \mathrm{DS}_{2}$-VASc score and AF duration in 21,768 patients with implantable cardiovascular devices who were not anticoagulated [70]. Both the increase in AF duration and $\mathrm{CHA}_{2} \mathrm{DS}_{2}$-VASc score were significantly associated with an annualized risk of S/SE. Although the $\mathrm{S} / \mathrm{SE}$ rates were low in patients with a $\mathrm{CHA}_{2} \mathrm{DS}_{2}-\mathrm{VASc}$ score of 0 to 1 regardless of device-detected $\mathrm{AF}$ duration, the stroke risk crossed an actionable threshold (defined as $>1 \%$ /year) in patients with a CHA2DS2-VASc of 2 with $>23.5 \mathrm{~h}$ of AF, with a $\mathrm{CHA}_{2} \mathrm{DS}_{2}$-VASc score of 3-4 with $>6$ min of $\mathrm{AF}$, and with a $\mathrm{CHA}_{2} \mathrm{DS}_{2}$-VASc score $\geq 5$ even with no AF. In patients with a daily AF duration between $6 \mathrm{~min}$ and $23.5 \mathrm{~h}$, a $\mathrm{CHA}_{2} \mathrm{DS}_{2}$-VASc score $>3$ is required to justify OAT, while an AF burden $>23.5 \mathrm{~h}$ would justify OAC at a CHA2DS2-VASc score of 2. Thus, $\mathrm{AF}$ duration, as detected on implantable cardiac devices, and $\mathrm{CHA}_{2} \mathrm{DS}_{2}$-VASc risk score can be used to define the threshold required for the initiation and/or maintenance of OAT in patients with underlying stroke risk factors. Furthermore, this study showed that in patients with elevated $\mathrm{CHA}_{2} \mathrm{DS}_{2}$-VASc score, some strokes may not be caused by AF directly, but may represent a marker for other stroke risk factors and vascular mechanisms with which AF is frequently associated.
After all these considerations, it is generally accepted that OAT should not be discontinued after CAAF in the following patients:

(1) At very high risk of stroke, such as those with valvular $\mathrm{AF}$ (mitral stenosis or valvular disease requiring surgery), hypertrophic cardiomyopathy, cardiac amyloidosis, large LA $(>5 \mathrm{~cm})$ which remains dilated after ablation, thrombus in the LA appendage, or LA spontaneous echocardiographic contrast post-ablation [53,71], even after apparently successful $\mathrm{AF}$ ablation, because in these patients recurrences of $\mathrm{AF}$ are more frequent than in the general population.

(2) At high risk of stroke $\left(\mathrm{CHA}_{2} \mathrm{DS}_{2}-\mathrm{VASc} 2 \geq 2\right.$ in men or $\geq 3$ in women), specially if they are elderly ( $>75$ years) or have prior stroke and/or TIA [54,72].

(3) At high risk of AF recurrences after CAAF, because many patients develop asymptomatic episodes of $\mathrm{AF}, \mathrm{AF}$ recurrences can occur months after $\mathrm{CAAF}$, and there is a lack of clear temporal association between $\mathrm{AF}$ recurrence and $\mathrm{S} /$ SE [73-75]. Among patients with a CHADS2 score of $\geq 3$, $26.9 \%$ of the recurrences occurred 2 years post-CAAF and the recurrence rates increased in later years [76]. Thus, we can not be sure that in patients with a $\mathrm{CHA}_{2} \mathrm{DS}_{2}$-VASc $\geq 2$ it is safe to stop OAT. A similar comment is valid for patients with asymptomatic AF episodes post-CAAF because they are exposed to an increased risk of S/SE if OAT is restarted too late. In the ASSERT study, subclinical atrial tachyarrhythmias (defined as episodes of atrial rate $\geq 190 \mathrm{bpm}$ ) lasting $>6 \mathrm{~min}$, as compared with no episodes, were associated with an increased risk of ischemic stroke or SE (HR 2.49; 
1.28-4.85; $P=0.007$ ) [77]. Similarly, in the TRENDS study, an atrial tachycardia/AF burden of $\geq 5.5 \mathrm{~h}$ on any given day during the antecedent 30 days appeared to double the thromboembolic event risk [78].

(4) Who are unable or unwilling to assess their heart rhythm regularly and reliably to screen for asymptomatic AF episodes [79].

Mobile health technologies are rapidly developing, including smart and wearable devices, external loop recorders, wearable patch monitors, and implantable electronic devices, to increase the likelihood of detecting asymptomatic AF, assess ventricular rate control, and correlate patient symptoms with heart rate $[80,81]$. In a retrospective cohort study of 1,965 adults with paroxysmal AF (median ATRIA stroke risk score $4, \mathrm{CHA}_{2} \mathrm{DS}_{2}$-VASc score 3), a greater cumulative burden of $\mathrm{AF}(\geq 11 \%)$ identified using up to 14-day continuous, noninvasive electrocardiographic monitoring was independently associated with a higher risk of subsequent ischemic stroke or arterial thromboembolism, while patients were not taking OAT, even after adjusting for known stroke risk factors [82]. Thus, AF burden following CAAF rather than just mere AF recurrence is a new parameter which could assist patients and physicians in having a more informed, shared decision-making discussion about stroke prevention strategies. Current limitations preventing the widespread adoption of wearable devices include the limited accuracy and insufficient outcome-based evidence to support clinical decision-making [80].

\section{Conclusions}

OAT (with VKAs or DOACs) decreases the risk of S/SE in patients with AF and stroke-risk factors, but long-term OAT can also result in severe bleeding complications. Unfortunately, at the present time there is no information from prospective RCTs to recommend whether it is safe or not to discontinue OAT therapy after successful CAAF in patients with intermediate-to-high stroke risk. Therefore, the decision of whether OAT can be safely discontinued post-CAAF remains controversial, but it can be considered in patients at intermediate clinical risk of S/SE on an individual-case basis considering the risk/benefit ratio and patients' preferences. Thus, there is an unmet need of solid evidence coming from large, long-term, prospective RCTs designed to properly answer this question. Furthermore, the existing differences between the pharmacological characteristics of DOACs and between the different procedures currently used to perform CAAF emphasize the need for more information about the optimal DOAC therapy in different patient populations and for each catheter ablation device. We hope that ongoing trials can shed some light and provide more definitive guidance on which is the best OAT regimen and in which populations it is safe or not to discontinue OAT after successful CAAF.

Acknowledgements They were provided in the front page of the MS. This work was supported by Grants from the Institute of Health Carlos III (CB16/11/00303), Ministerio de Economía y Competitividad (SAF2017-88116-P) and Comunidad Autónoma de Madrid (B2017/ BMD-3738)

Authors' Contributions Both authors contribute equally to the manuscript.

Data Availability Not applicable to this manuscript.

\section{Declarations}

Ethics Approval and Consent to Participate Not applicable to this manuscript.

Informed Consent Not applicable to this manuscript.

Consent for Publication Not applicable to this manuscript.

Competing Interest The authors declare that there are no conflicts of interest.

Research Involving Human Participants and/or Animals Not applicable to this manuscript.

\section{References}

1. Calkins H, Hindricks G, Cappato R, Kim YH, Saad EB, Aguinaga $\mathrm{L}$, et al. HRS/EHRA/ECAS/APHRS/SOLAECE expert consensus statement on catheter and surgical ablation of atrial fibrillation. Europace. 2018;20:e1-160.

2. January CT, Wann LS, Calkins H, Chen LY, Cigarroa JE, Cleveland JC Jr, et al. 2019 AHA/ACC/HRS focused update of the 2014 AHA/ACC/HRS guideline for the Management of Patients with Atrial Fibrillation: a report of the American College of Cardiology/American Heart Association task force on clinical practice guidelines and the Heart Rhythm Society. Heart Rhythm. 2019;16:e66-93.

3. Hindricks G, Potpara T, Dagres N, Arbelo E, Bax JJ, BlomströmLundqvist C, et al. ESC Scientific Document Group. 2020 ESC Guidelines for the diagnosis and management of atrial fibrillation developed in collaboration with the European Association for Cardio-Thoracic Surgery (EACTS). Eur Heart J. 2021;42:373-498.

4. Virani SS, Alonso A, Aparicio HJ, Benjamin EJ, Bittencourt MS, Callaway CW, et al. American Heart Association Council on Epidemiology and Prevention Statistics Committee and Stroke Statistics Subcommittee. Heart Disease and Stroke Statistics-2021 Update: a Report From the American Heart Association. Circulation. 2021;143:e254-743.

5. Lin HJ, Wolf PA, Kelly-Hayes M, Beiser AS, Kase CS, Benjamin EJ, et al. Stroke severity in atrial fibrillation The Framingham Study. Stroke. 1996;27:1760-4.

6. Hayden DT, Hannon N, Callaly E, Ní Chróinín D, Horgan G, Kyne L, et al. Rates and determinants of 5-year outcomes after atrial fibrillation-related stroke: a population study. Stroke. 2015;46:3488-93. 
7. Arbelo E, Brugada J, Blomstrom-Lundqvist C, Laroche C, Kautzner J, Pokushalov E, et al., on the behalf of the ESC EHRA Atrial Fibrillation Ablation Long-term Registry Investigators. Contemporary management of patients undergoing atrial fibrillation ablation: in-hospital and 1-year follow-up findings from the ESC-EHRA atrial fibrillation ablation long-term registry. Eur Heart J. 2017;38:1303-16.

8. Nyong J, Amit G, Adler AJ, Owolabi OO, Perel P, PrietoMerino D, et al. Efficacy and safety of ablation for people with nonparoxysmal atrial fibrillation. Cochrane Database Syst Rev. 2016;11:CD012088.

9. Siontis KC, Ioannidis JPA, Katritsis GD, Noseworthy PA, Packer DL, Hummel JD, et al. Radiofrequency Ablation Versus Antiarrhythmic Drug Therapy for Atrial Fibrillation: MetaAnalysis of Quality of Life, Morbidity, and Mortality. JACC Clin Electrophysiol. 2016;2:170-80.

10. Packer DL, Mark DB, Robb RA, Monahan KH, Bahnson TD, Poole JE, et al. Effect of catheter ablation vs antiarrhythmic drug therapy on mortality, stroke, bleeding, and cardiac arrest among patients with atrial fibrillation: the CABANA Randomized Clinical Trial. JAMA. 2019;321:1261-74.

11. Vassilikos VP, Pagourelias ED, Laroche C, Blomström-Lundqvist C, Kautzner J, Maggioni AP, et al. AFA LT registry investigators group. Impact of centre volume on atrial fibrillation ablation outcomes in Europe: a report from the ESC EHRA EORP Atrial Fibrillation Ablation Long-Term (AFA LT) Registry. Europace. 2021;23:49-58.

12. Marrouche NF, Brachmann J, Andresen D, Siebels J, Boersma L, Jordaens L, et al; CASTLE-AF Investigators. Catheter Ablation for Atrial Fibrillation with Heart Failure. N Engl J Med. 2018;378:417-427.

13. Di Biase L, Mohanty P, Mohanty S, et al. Ablation versus amiodarone for treatment of persistent atrial fibrillation in patients with congestive heart failure and an implanted device: results from the AATAC multicenter randomized trial. Circulation. 2016;133:1637-44.

14. Samuel M, Abrahamowicz M, Joza J, Beauchamp ME, Essebag V, Pilote L. Long-term effectiveness of catheter ablation in patients with atrial fibrillation and heart failure. Europace. 2020;22:739-47.

15. Prabhu S, Taylor AJ, Costello BT, Kaye DM, McLellan AJA, Voskoboinik A, et al. Catheter ablation versus medical rate control in atrial fibrillation and systolic dysfunction: the CAMERAMRI study. J Am Coll Cardiol. 2017;70:1949-61.

16. Noseworthy PA, Van Houten HK, Gersh BJ, Packer DL, Friedman PA, Shah ND, et al. Generalizability of the CASTLE-AF trial: Catheter ablation for patients with atrial fibrillation and heart failure in routine practice. Heart Rhythm. 2020;17:1057-65

17. Barra S, Baran J, Narayanan K, Boveda S, Fynn S, Heck P, et al. Association of catheter ablation for atrial fibrillation with mortality and stroke: a systematic review and meta-analysis. Int J Cardiol. 2018;266:136-42.

18. Asad ZUA, Yousif A, Khan MS, Al-Khatib SM, Stavrakis S. Catheter ablation versus medical therapy for atrial fibrillation: a systematic review and meta-analysis of randomized controlled trials. Circ Arrhythm Electrophysiol. 2019;12:e007414.

19. Briceño DF, Madan N, Romero J, Londoño A, Villablanca PA, Natale A, et al. Thromboembolic and bleeding risks in patients undergoing atrial fibrillation ablation: oral anticoagulation perspectives. Expert Opin Drug Saf. 2017;16:769-77.

20. Cappato R, Calkins H, Chen SA, Davies W, Iesaka Y, Kalman $\mathrm{J}$, et al. Updated worldwide survey on the methods, efficacy, and safety of catheter ablation for human atrial fibrillation. Circ Arrhythm Electrophysiol. 2010;3:32-8.
21. De Greef Y, Stroker E, Schwagten B, Kupics K, De Cocker J, Chierchia GB, et al. Complications of pulmonary vein isolation in atrial fibrillation: predictors and comparison between four different ablation techniques: results from the Middelheim PVI-registry. Europace. 2018;20:1279-86.

22. Steinbeck G, Sinner MF, Lutz M, Müller-Nurasyid M, Kääb S, Reinecke H. Incidence of complications related to catheter ablation of atrial fibrillation and atrial flutter: a nationwide in-hospital analysis of administrative data for Germany in 2014. Eur Heart J. 2018;39:4020-9.

23. Santangeli P, Di Biase L, Horton R, Burkhardt JD, Sanchez J, AlAhmad A, et al. Ablation of atrial fibrillation under therapeutic warfarin reduces periprocedural complications: evidence from a meta-analysis. Circ Arrhythm Electrophysiol. 2012;5:302-11.

24. Di Biase L, Burkhardt JD, Santangeli P, Mohanty P, Sanchez JE, Horton R, et al. Periprocedural stroke and bleeding complications in patients undergoing catheter ablation of atrial fibrillation with different anticoagulation management: results from the Role of Coumadin in Preventing Thromboembolism in Atrial Fibrillation (AF) Patients Undergoing Catheter Ablation (COMPARE) randomized trial. Circulation. 2014;129:2638-44.

25. De Caterina R, Husted S, Wallentin L, Andreotti F, Arnesen H, Bachmann F, et al. Vitamin $\mathrm{K}$ antagonists in heart disease: current status and perspectives (Section III). Position paper of the ESC working group on thrombosis Task Force on anticoagulants in heart disease. Thromb Haemost. 2013;110:1087-107.

26. Ruff CT, Giugliano RP, Braunwald E, Hoffman EB, Deenadayalu N, Ezekowitz MD, et al. Comparison of the efficacy and safety of new oral anticoagulants with warfarin in patients with atrial fibrillation: a meta-analysis of randomised trials. Lancet. 2014;383:955-62.

27. Cappato R,Marchlinski FE,Hohnloser SH, Naccarelli GV, Xiang J, Wilber DJ, et al. VENTURE-AF Investigators Uninterrupted rivaroxaban vs uninterrupted vitamin $\mathrm{K}$ antagonists for catheter ablation in non-valvular atrial fibrillation. Eur Heart J. 2015;36:1805-11.

28. Kuwahara T, Abe M, Yamaki M, Fujieda H, Abe Y, Hashimoto $\mathrm{K}$, et al. Apixaban versus warfarin for the prevention of periprocedural cerebral thromboembolism in atrial fibrillation ablation: multicenter prospective randomized study. J Cardiovasc Electrophysiol. 2016;27:549-54.

29. Calkins H, Willems S, Gerstenfeld EP, Verma A, Schilling R, Hohnloser SH, et al. Grimaldi M; RE-CIRCUIT investigators. Uninterrupted Dabigatran versus warfarin for ablation in atrial fibrillation. N Engl J Med. 2017;376:1627-36.

30. Kirchhof P, Haeusler KG, Blank B, De Bono J, Callans D, Elvan A, et al. Apixaban in patients at risk of stroke undergoing atrial fibrillation ablation. Eur Heart J. 2018;39:2942-55.

31. Reynolds MR, Allison JS, Natale A, Weisberg IL, Ellenbogen $\mathrm{KA}$, Richards M, et al. A prospective randomized trial of apixaban dosing during atrial fibrillation ablation: the AEIOU Trial. JACC Clin Electrophysiol. 2018;4:580-8.

32. Hohnloser SH, Camm J, Cappato R, Diener H-C, Heidbüchel H, Mont $\mathrm{L}$, et al. Uninterrupted edoxaban vs. vitamin $\mathrm{K}$ antagonists for ablation of atrial fibrillation: the ELIMINATE-AF trial. Eur Heart J. 2019;40:3013-21.

33. Zhao Y, Yang Y, Tang X, Yu X, Zhang L, Xiao H. New oral anticoagulants compared to warfarin for perioperative anticoagulation in patients undergoing atrial fibrillation catheter ablation: a metaanalysis of continuous or interrupted new oral anticoagulants during ablation compared to interrupted or continuous warfarin. $\mathrm{J}$ Interv Card Electrophysiol. 2017;48:267-82.

34. Atti V, Turagam MK, Viles-Gonzalez JF, Lakkireddy D. Anticoagulation After Catheter Ablation of Atrial Fibrillation: is it time to Discontinue in Select Patient Population? J Atr Fibrillation. 2018;11:2092. 
35. Brunetti ND, Tarantino N, De Gennaro L, Correale M, Santoro F, Di Biase M. Direct oral anti-coagulants compared to vitamin-K antagonists in cardioversion of atrial fibrillation: an updated metaanalysis. J Thromb Thrombolysis. 2018;45:550-6.

36. Zhao Y, Lu Y, Qin Y. A meta-analysis of randomized controlled trials of uninterrupted periprocedural anticoagulation strategy in patients undergoing atrial fibrillation catheter ablation. Int J Cardiol. 2018;270:167-71.

37. Cardoso R, Knijnik L, Bhonsale A, Miller J, Nasi G, Rivera M, et al. An updated meta-analysis of novel oral anticoagulants versus vitamin $\mathrm{K}$ antagonists for uninterrupted anticoagulation in atrial fibrillation catheter ablation. Heart Rhythm. 2018;15:107-15.

38. Proietti R, AlTurki A, Di Biase L, China P, Forleo G, Corrado A, Marras E, Natale A, Themistoclakis S. Anticoagulation after catheter ablation of atrial fibrillation: an unnecessary evil? A systematic review and meta-analysis. J Cardiovasc Electrophysiol. 2019;30:468-78.

39. Romero J, Cerrud-Rodriguez RC, Alviz I, Diaz JC, Rodriguez D, Arshad S, et al. Significant benefit of uninterrupted DOACs versus VKA during catheter ablation of atrial fibrillation. JACC Clin Electrophysiol. 2019;5:1396-405.

40. Romero J, Cerrud-Rodriguez RC, Diaz JC, Rodriguez D, Arshad $\mathrm{S}$, Alviz I, et al. Oral anticoagulation after catheter ablation of atrial fibrillation and the associated risk of thromboembolic events and intracranial hemorrhage: a systematic review and meta-analysis. J Cardiovasc Electrophysiol. 2019;30:1250-7.

41. Ottóffy M, Mátrai P, Farkas N, Hegyi P, Czopf L, Márta K, Garami A, Balaskó M, Pótóné-Oláh E, Mikó A, Rostás I, Wobbe $\mathrm{B}$, Habon T. Uninterrupted or minimally interrupted direct oral anticoagulant therapy is a safe alternative to vitamin $\mathrm{k}$ antagonists in patients undergoing catheter ablation for atrial fibrillation: an updated meta-analysis. J Clin Med. 2020;9:3073.

42. Yang P, Wang C, Ye Y, Huang T, Yang S, Shen W, et al. Interrupted or uninterrupted oral anticoagulants in patients undergoing atrial fibrillation ablation. Cardiovasc Drugs Ther. 2020;34:371-81

43. Hohnloser SH, Camm AJ. Safety and efficacy of dabigatran etexilate during catheter ablation of atrial fibrillation: a meta-analysis of the literature. Europace. 2013;15:1407-11.

44. Providência R, Marijon E, Albenque JP, Combes S, Combes N, Jourda F, et al. Rivaroxaban and dabigatran in patients undergoing catheter ablation of atrial fibrillation. Europace. 2014;16:1137-44.

45. Winkle RA, Mead RH, Engel G, Kong MH, Patrawala RA. Periprocedural interrupted oral anticoagulation for atrial fibrillation ablation: comparison of aspirin, warfarin, dabigatran, and rivaroxaban. Europace. 2014;16:1443-9.

46. Steffel J, Verhamme P, Potpara TS, Albaladejo P, Antz M, Desteghe L, et al. The 2018 European Heart Rhythm Association Practical Guide on the use of non-vitamin K antagonist oral anticoagulants in patients with atrial fibrillation. Eur Heart J. 2018;39:1330-93.

47. Wagstaff AJ, Overvad TF, Lip GYH, Lane DA. Is female sex a risk factor for stroke and thromboembolism in patients with atrial fibrillation? A systematic review and meta-analysis. QJM. 2014;107:955-67.

48. Nielsen PB, Larsen TB, Skjoth F, Overvad TF, Lip GY. Stroke and thromboembolic event rates in atrial fibrillation according to different guideline treatment thresholds: a nationwide cohort study. Sci Rep. 2016;6:27410.

49. Nuotio I, Hartikainen JEK, Grönberg T, Biancari F, Airaksinen KE. Time to cardioversion for acute atrial fibrillation and thromboembolic complications. JAMA. 2014;312:647-9.

50. Garg A, Khunger M, Seicean S, Chung MK, Tchou PJ. Incidence of thromboembolic complications within 30 days of electrical cardioversion performed within 48 hours of atrial fibrillation onset. J Am Coll Cardiol EP. 2016;2:487-94.

51. Borre ED, Goode A, Raitz G, Shah B, Lowenstern A, Chatterjee R, et al. Predicting thromboembolic and bleeding event risk in patients with non-valvular atrial fibrillation: a systematic review. Thromb Haemost. 2018;118:2171-87.

52. Nührich JM, Kuck KH, Andresen D, Steven D, Spitzer SG, Hoffmann E, et al. Oral anticoagulation is frequently discontinued after ablation of paroxysmal atrial fibrillation despite previous stroke: data from the German Ablation Registry. Clin Res Cardiol. 2015;104:463-70.

53. Freeman JV, Shrader P, Pieper KS, Allen LA, Chan PS, Fonarow GC, et al. Outcomes and anticoagulation use after catheter ablation for atrial fibrillation. Circ Arrhythm Electrophysiol. 2019;12:e007612.

54. Mardigyan V, Verma A, Birnie D, Guerra P, Redfearn D, Becker $\mathrm{G}$, et al. Anticoagulation management pre- and post atrial fibrillation ablation: a survey of Canadian centres. Can J Cardiol. 2013;29:219-23.

55. Oral H, Chugh A, Ozaydin M, Good E, Fortino J, Sankaran S, Reich S, Igic P, Elmouchi D, Tschopp D, Wimmer A, Dey S, Crawford T, Pelosi F Jr, Jongnarangsin K, Bogun F, Morady F. Risk of thromboembolic events after percutaneous left atrial radiofrequency ablation of atrial fibrillation. Circulation. 2006;114:759-65.

56. Themistoclakis S, Corrado A, Marchlinski FE, Jais P, Zado E, Rossillo A, Di Biase L, Schweikert RA, Saliba WI, Horton R, Mohanty P, Patel D, Burkhardt DJ, Wazni OM, Bonso A, Callans DJ, Haissaguerre M, Raviele A, Natale A. The risk of thromboembolism and need for oral anticoagulation after successful atrial fibrillation ablation. J Am Coll Cardiol. 2010;55:735-43.

57. Yagishita A, Takahashi Y, Takahashi A, Fujii A, Kusa S, Fujino $\mathrm{T}$, et al. Incidence of late thromboembolic events after catheter ablation of atrial fibrillation. Circ J. 2011;75:2343-9.

58. Winkle RA, Mead RH, Engel G, Kong MH, Patrawala RA. Discontinuing anticoagulation following successful atrial fibrillation ablation in patients with prior strokes. J Interv Card Electrophysiol. 2013;38:147-53.

59. Karasoy D, Gislason GH, Hansen J, Johannessen A, Køber L, Hvidtfeldt M, et al. Oral anticoagulation therapy after radiofrequency ablation of atrial fibrillation and the risk of thromboembolism and serious bleeding: long-term follow-up in nationwide cohort of Denmark. Eur Heart J. 2015;36:307-14.

60. Noseworthy PA, Yao X, Deshmukh AJ, Van Houten H, Sangaralingham LR, Siontis KC, et al. Patterns of anticoagulation use and cardioembolic risk after catheter ablation for atrial fibrillation. $\mathrm{J}$ Am Heart Assoc. 2015;4:e002597.

61. Gallo C, Battaglia A, Anselmino M, Bianchi F, Grossi S, Nangeroni $\mathrm{G}$, et al. Long-term events following atrial fibrillation rate control or transcatheter ablation: a multicenter observational study. J Cardiovasc Med (Hagerstown). 2016;17:187-93.

62. Själander S, Holmqvist F, Smith JG, Platonov PG, Kesek M, Svensson PJ, et al. Assessment of use vs discontinuation of oral anticoagulation after pulmonary vein isolation in patients with atrial fibrillation. JAMA Cardiol. 2017;2:146-52.

63. Liang JJ, Elafros MA, Mullen MT, Muser D, Hayashi T, Enriquez A, et al. Anticoagulation use and clinical outcomes after catheter ablation in patients with persistent and longstanding persistent atrial fibrillation. J Cardiovasc Electrophysiol. 2018;29:823-32.

64. Yang WY, Du X, Jiang C, He L, Fawzy AM, Wang L, et al. The safety of discontinuation of oral anticoagulation therapy after apparently successful atrial fibrillation ablation: a report from the Chinese Atrial Fibrillation Registry study. Europace. 2020;22:90-9. 
65. Chao TF, Lip GYH, Lin YJ, Chang SL, Lo LW, Hu YF, et al. Incident risk factors and major bleeding in patients with atrial fibrillation treated with oral anticoagulants: a comparison of baseline, follow-up and Delta HAS-BLED scores with an approach focused on modifiable bleeding risk factors. Thromb Haemost. 2018;118:768-77.

66. Bohm M, Ezekowitz MD, Connolly SJ, Eikelboom JW, Hohnloser SH, Reilly PA, et al. Changes in renal function in patients with atrial fibrillation: an analysis from the RE-LY trial. J Am Coll Cardiol. 2015;65:2481-93.

67. Chao TF, Liao JN, Tuan TC, Lin YJ, Chang SL, Lo LW, et al. Incident co-morbidities in patients with atrial fibrillation initially with a CHA2DS2-VASc score of 0 (males) or 1 (females): implications for reassessment of stroke risk in initially 'lowrisk' patients. Thromb Haemost. 2019;119:1162-70.

68. Weijs B, Dudink E, de Vos CB, Limantoro I, Tieleman RG, Pisters R, et al. Idiopathic atrial fibrillation patients rapidly outgrow their low thromboembolic risk: a 10-year follow-up study. Neth Heart J. 2019;27:487-97.

69. Potpara TS, Larsen TB, Deharo JC, Rossvoll O, Dagres N, Todd D, et al. Oral anticoagulant therapy for stroke prevention in patients with atrial fibrillation undergoing ablation: results from the First European Snapshot Survey on Procedural Routines for Atrial Fibrillation Ablation (ESS-PRAFA). Europace. 2015;17:986-93.

70. Kaplan RM, Koehler J, Ziegler PD, Sarkar S, Zweibel S, Passman RS. Stroke risk as a function of atrial fibrillation duration and CHA2DS2-VASc score. Circulation. 2019;140:1639-46.

71. Riley MP, Zado E, Hutchinson MD, Lin D, Bala R, Garcia FC, et al. Risk of stroke or transient ischemic attack after atrial fibrillation ablation with oral anticoagulant use guided by ECG monitoring and pulse assessment. J Cardiovasc Electrophysiol. 2014;25:591-6.

72. Yanagisawa S, Inden Y, Fujii A, Ando M, Funabiki J, Murase $\mathrm{Y}$, et al. Uninterrupted direct oral anticoagulant and warfarin administration in elderly patients undergoing catheter ablation for atrial fibrillation: a comparison with younger patients. JACC Clin Electrophysiol. 2018;4:592-600.

73. Verma A, Champagne J, Sapp J, Essebag V, Novak P, Skanes AM, et al. Discerning the incidence of symptomatic and asymptomatic episodes of atrial fibrillation beforeand after catheter ablation (DISCERN AF). JAMA Intern Med. 2013;173:149-56.
74. Daoud EG, Glotzer TV, Wyse DG, Ezekowitz MD, Hilker C, Koehler J, et al. Temporal relationship of atrial tachyarrhythmias, cerebrovascular events, and systemic emboli on the basis of stored device data: a subgroup analysis of TRENDS. Heart Rhythm. 2011;8:1416-23.

75. Ganesan AN, Chew DP, Hartshorne T, Selvanayagam JB, Aylward PE, Sanders P, et al. The impact of atrial fibrillation type on the risk of thromboembolism, mortality, and bleeding: a systematic review and meta-analysis. Eur Heart J. 2016;37:1591-602.

76. Chao TF, Ambrose K, Tsao HM, Lin YJ, Chang SL, Lo LW, et al. Relationship between the CHADS2 score and risk of very late recurrences after catheter ablation of paroxysmal atrial fibrillation. Heart Rhythm. 2012;9:1185-91.

77. Healey JS, Connolly SJ, Gold MR, Israel CW, Van Gelder IC, Capucci A, et al.; ASSERT Investigators. Subclinical atrial fibrillation and the risk of stroke. N Engl J Med. 2012;366:120-9.

78. Glotzer TV, Daoud EG, Wyse DG, Singer DE, Ezekowitz MD, Hilker C, Miller C, Qi D, Ziegler PD. The relationship between daily atrial tachyarrhythmia burden from implantable device diagnostics and stroke risk: the TRENDS study. Circ Arrhythm Electrophysiol. 2009;2:474-80.

79. Liang JJ, Callans DJ. Can anticoagulation be stopped after ablation of atrial fibrillation? Curr Cardiol Rep. 2020;22:58.

80. Cheung CC, Krahn AD, Andrade JG. The emerging role of wearable technologies in detection of arrhythmia. Can J Cardiol. 2018:34:1083-7.

81. Jones NR, Taylor CJ, Hobbs FDR, Bowman L, Casadei B. Screening for atrial fibrillation: a call for evidence. Eur Heart J. 2020;41:1075-85.

82. Go AS, Reynolds K, Yang J, Gupta N, Lenane J, Sung SH, et al. Association of burden of atrial fibrillation with risk of ischemic stroke in adults with paroxysmal atrial fibrillation: the KPRHYTHM Study. JAMA Cardiol. 2018;3:601-8.

Publisher's Note Springer Nature remains neutral with regard to jurisdictional claims in published maps and institutional affiliations. 